\title{
Research and application of multifunctional flushing fluid
}

\author{
Miaosen Lu ${ }^{1}$, Guoqiang Huang ${ }^{2}$, Zhonghua Shao ${ }^{1}$, Mei Bin ${ }^{1}$, Shuai Zhang ${ }^{3}$, Wenhua Han ${ }^{4}$, Shasha Liu ${ }^{1}$, Zhiqiang Wang ${ }^{1}$, \\ Tiantian Zhang ${ }^{1}$ \\ ${ }^{1}$ Petroleum Production Engineering Research Institute of Huabei Oilfield Company, Renqiu, Hebei Province, 062552 \\ ${ }^{2}$ Materils Branch of Huabei Petroleum administration co., ltd. Renqiu, Hebei Province, 062550 \\ ${ }^{3}$ The Third Exploit Factory of Huabei Oilfield Company, Hejian, Hebei Province, 062450 \\ ${ }^{4}$ The Forth Exploit Factory of Huabei Oilfield Company, Langfang, Hebei Province, 062552
}

\begin{abstract}
In the process of oilfield development, the reservoir of oil wells were polluted due to well flushing and pump inspection, which resulted in long recovery period of oil well production after operation, or even difficult recovery of production. According to the states mentioned above, researchers developed XST and XSK series multifunctional flushing fluid, which had the function of anti-swelling, anti-pollution, as well as cleaning functions. The laboratory experiments showed that the oil washing efficiency $\geq 80 \%$, antiswelling rate $\geq 70 \%$, as well as the damage value of reservoir permeability $\leq 30 \%$. The above formula was applied in J902 oil well, which achieved great success. Not only the fishing tools went in smoothly, but also the recovery period after the well flushing operation was shortened to 4 days, which effectively reduced the impact of the well flushing operation on the well production.
\end{abstract}

\section{Research background}

In all oil production plants of HB Oil field, oil Wells pollute reservoirs due to well washing, pump inspection and other operations, resulting in long recovery period of production after operation and even difficult recovery ${ }^{[1-4]}$. From January 2018 to May 2019 in THE CB operation area alone, the number of well flushing and pump inspection operations reached 177 Wells, affecting the output of 15,000 tons.

In order to prevent the reservoir pollution in the well flushing process, the types of reservoir damage was firstly identified by analysis. And then, the functional requirements of flushing fluids were clarified. Finally, the highly efficient well flushing liquid formula was independently developed, which had the function of integrating anti-swelling, cleaning and other functions. For oil products with high wax content, the oil washing efficiency is $\geq 80 \%$, Anti-expansion rate $\geq 70 \%$, Damage value of reservoir permeability $\leq 30 \%$, the operation recovery period is shortened to 4 days, The effect of well flushing operation on well production is reduced effectively.

\section{The experiment part}

\subsection{Experimental instruments and materials}

\subsubsection{Experimental instruments}

JK-MSH-PRO-6B magnetic stirrer, H-101 electric thermostatic air blast drying box, 5804R high-speed frozen centrifuge, IS34E_H_OCE balance, core gripper

Dehydrated crude oil, field oil sample Q42 of HB Oilfield; Recycled sewage, and recycled sewage used in water injection Wells; Surfactants A, B, C, D, E, F, industrial grade, Tiancheng Industrial chemical Co. of Hebei Province, LTD, TDC, Tianjin Xinxiang Oil and Gas Technology Co., LTD.JK, JA, $\mathrm{KCl}$ (industrial grade), $\mathrm{NH}_{4} \mathrm{Cl}$ (industrial grade), Tiancheng Industrial Chemical Co. of Hebei Province, LTD.N80 steel sheet.

\subsection{Experimental Steps}

\subsubsection{Oil washing experiment by hanging film method}

(1) Weigh the prepared N80 stainless steel specimen, accurated to $\pm 0.1 \mathrm{mg}$, recorded as $\mathrm{W}_{0}$;

(2) Soak the weight steel sheet in petroleum ether for 24h, In order to improve the lipophilic steel sheet;

(3) After wiping the steel sheet with filter paper, soak it in an oil sample for 24 hours, and then remove the hanging piece, hang with s-hook on the test rack, dry

el_lumiaosen@petrochina.com.cn 
naturally at room temperature (72 hours), wipe off the bottom oil and weigh with filter paper, and record as $\mathrm{W}_{1}$;

(4) In a $250 \mathrm{~mL}$ beaker, pour $200 \mathrm{ml}$ of $1 \%$ flushing fluid into the prepared well. Then the beaker was placed in a water bath pot hole at $(60 \pm 2){ }^{\circ} \mathrm{C}$. Keep the flushing liquid solution temperature at $(60 \pm 2){ }^{\circ} \mathrm{C}$, the test piece of the crude oil is placed vertically into the well flushing fluid. Immediately swing the test piece along the beaker diameter, at the speed of one beaker diameter $(71 \mathrm{~mm})$ per second, pendulum wash 60 times. The test piece was taken out, weighed and recorded as $\mathrm{W}_{2}$.

(5) Calculate the oil washing efficiency, and then calculating the oil washing efficiency.

The oil washing efficiency is calculated according to formula (1): The oil washing efficiency $=\left(\mathrm{W}_{1}-\mathrm{W}_{2}\right) /\left(\mathrm{W}_{1}\right.$ $\left.\mathrm{V}_{0}\right) \times 100 \%$

In the equation: $\eta$ - oil washing efficiency, $\% ; \mathrm{W}_{0}-$ quality of steel sheet before contamination, $\mathrm{g} ; \mathrm{W}_{1}-$ Quality of steel sheet after contamination, $\mathrm{g} ; \mathrm{W}_{2}-$ Quality of steel sheet cleaned by flushing fluid, $\mathrm{g}$.

\subsubsection{Compatibility experiment}

With the help of the previous research results of composite anti-expansion technology, add anti-swelling agent to the high-efficiency well flushing fluid in a certain proportion, observe whether the solution has stratification, precipitation and other phenomena.

\subsubsection{Aging oil dissolution test}

Under the temperature of $60{ }^{\circ} \mathrm{C}$, taking $1 \mathrm{~g}$ block aged oil sample, and then dissolving in $200 \mathrm{~mL}$ of $1 \%$ flushing fluid. Let stand after $0.5 \mathrm{~h}$. Observe the dispersion effect of scale sample in the flushing fluid. This method is used to evaluate the stripping and dissolving ability of scale samples by flushing fluid. Specific experimental steps:

(1) In a $250 \mathrm{ml}$ beaker, $200 \mathrm{~mL}$ of $1 \%$ flushing fluid was prepared;

(2) Weigh a massive scale sample of about $1 \mathrm{~g}$, dissolve in the well flushing fluid, let stand for $0.5 \mathrm{~h}$, take photos to record the initial dissolution, and the shape of the scale after half an hour of dissolution;

(3) Write down the dispersion of scale samples in the flushing fluid. Evaluate whether the flushing fluid has the ability to peel and dissolve the scale sample.

\subsubsection{Evaluation experiment of anti-inflation ability}

(1) Weigh $0.50 \mathrm{~g}$ bentonite powder, accurately reach $0.01 \mathrm{~g}$, put it into a $10 \mathrm{~mL}$ centrifuge tube, add $10 \mathrm{~mL}$ clay stabilizer solution, fully stir it with a fine glass rod/plastic wrapped paper clipping, shake well, let it stand for $2 \mathrm{~h}$ at room temperature, put it into a centrifuge, centrifuge it for $15 \mathrm{~min}$ at a speed of $1500 \mathrm{r} / \mathrm{min}$, and read the expanded bentonite volume V1;

(2) Repeat step (1), replace the clay stabilizer solution with $10 \mathrm{~mL}$ water, determination of the expansive volume $\mathrm{V} 2$ of bentonite in water

(3) Repeat step (1), replace clay stabilizer solution with $10 \mathrm{~mL}$ aviation kerosene, determination of expansion volume $\mathrm{V}_{0}$ of bentonite in kerosene;

The anti-expansion rate is calculated according to the following formula: $\mathrm{B} 1=\left(\mathrm{V}_{2}-\mathrm{V}_{1}\right) /\left(\mathrm{V}_{2}-\mathrm{V}_{0}\right) \times 100 \%$

In the equation: $\mathrm{B}_{1}$-anti-expansion rate, $\% ; \mathrm{V}_{1}$ swelling volume of bentonite in clay stabilizer solution, $\mathrm{mL} ; \mathrm{V}_{2}$ - swelling volume of bentonite in water, $\mathrm{mL} ; \mathrm{V}_{0}-$ swelling volume of bentonite in kerosene, $\mathrm{mL}$.

\subsubsection{Core injury evaluation experiment}

(1) Core experimental evaluation method, according to SY/T5336-88 Recommended Practice for Conventional Core Analysis.Selecting natural cores from multiple target blocks, by cutting, cleaning, measuring permeability, measuring length and diameter, saturation samples, calculating core pore volume. Core water phase permeability $\mathrm{K} 0$ is measured by standard brine flooding to pressure stabilization, displacing 10 to 15 times the pore volume of sewage, then use standard saline flooding until pressure stabilizes, core water phase permeability K1 after contamination was measured, permebility before and after pollution, calculated core damage rate, judge the degree of core damage.

(2) Repeat the above steps (1), replace the sewage with the new well flushing fluid, and evaluate the damage degree of the new well flushing fluid to the core.

\section{Experimental results and discussion}

\subsection{Determination of test temperature of hanging film washing oil}

To determine the appropriate experimental temperature, the crude oil from well J95-4 was taken as the cleaning object in the laboratory experiment. At different experimental temperatures, the crude oil cleaning capacity of N80 steel sheet by sewage was investigated, the experimental results are shown in the figure below.

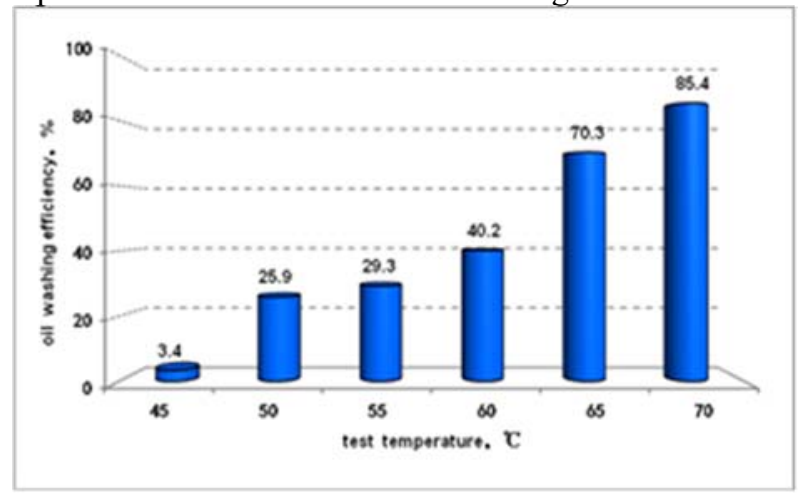

Fig.1 Effect of sewage on cleaning efficiency of crude oil under different experimental temperatures

The experimental results show that the higher the temperature is, the higher the efficiency of cleaning oil will be. When the water temperature is above $60^{\circ} \mathrm{C}$, the efficiency of clean water oil reaches $40.2 \%$, which is already high, and it is difficult to characterize the effect of pharmaceutical oil washing. Therefore, the simulated temperature in the laboratory experiment was set at $60^{\circ} \mathrm{C}$. 


\subsection{Research on efficient well flushing fluid base formula}

In the research and development of efficient well flushing fluid base formula. Firstly, 6 kinds of surfactants with

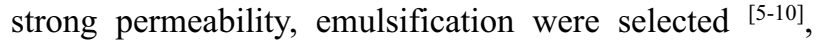
under the temperature of $60^{\circ} \mathrm{C}$, different surfactant single agents were investigated, the oil washing efficiency under the conditions of mass concentration of $0.6 \%, 0.8 \%$ and $1.0 \%$, respectively. The results show that, at different concentrations, compared to other agents, both surfactants $\mathrm{B}$ and $\mathrm{D}$ have excellent cleaning efficiency.

D and B surfactants with high oil washing effect when used alone are optimized, with the help of the combination of Yin and non-ionic surfactant, they are in different proportions, to investigate the cleaning ability of the compound reagent to crude oil, the experimental results are shown in Figure 3-10. And it turns out, anionic surfactant $\mathrm{D}$ and non-ionic surfactant $\mathrm{B}$, and the mass ratio is $1: 4$ and the total mass concentration is $1 \%$, the oil washing efficiency of the reagent at $60^{\circ} \mathrm{C}$ is $78 \%$.

On the basis of the above experiments, with functional additives to suspend and stabilize solid dirt and oil droplets, the role of complexing heavy metal ions. Finally, XS-1, the effective well flushing fluid base formula, was obtained: $0.2 \%$ anionic surfactant $\mathrm{D}+0.8 \%$ non-ionic surfactant $\mathrm{B}+0.2 \%$ additive $\mathrm{ZB}$, the oil washing efficiency of the composite system reaches $85 \%$. The efficiency of oil cleaning is improved by $25 \% \sim 30 \%$ than that of single agent.

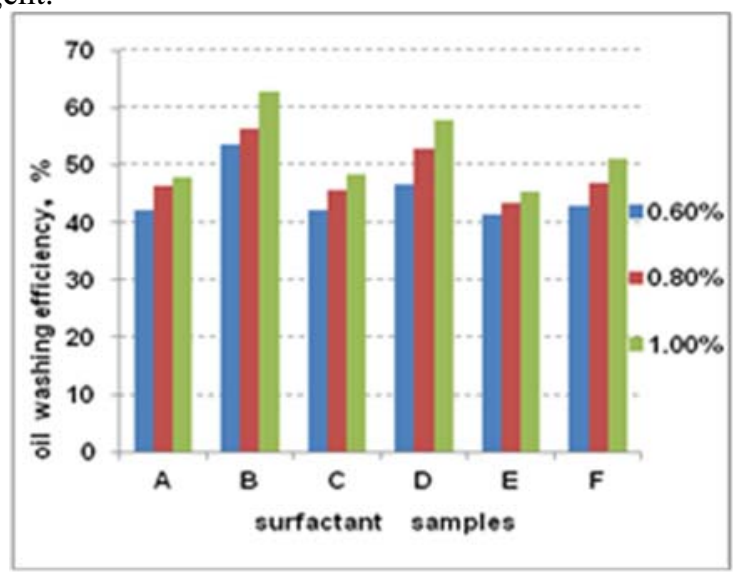

Fig.2 Influence of flushing fluid main agent on crude oil washing efficiency

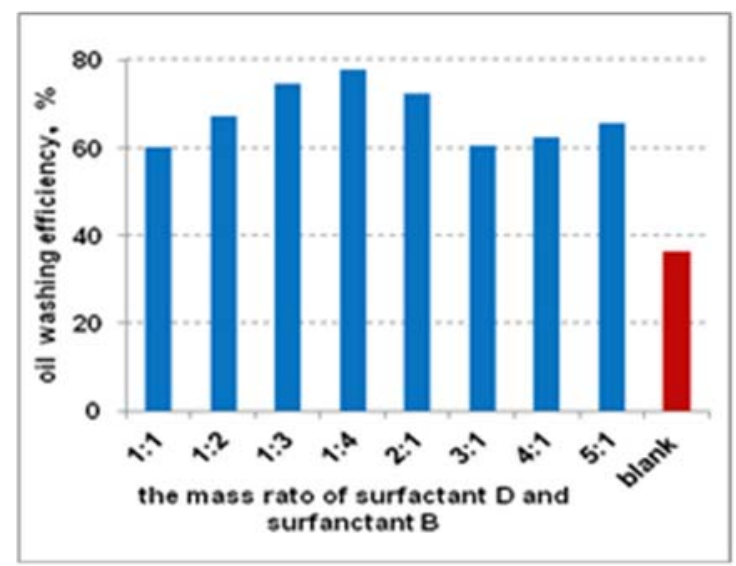

Fig.3 Influence of main agent compound on oil washing efficiency of crude oil

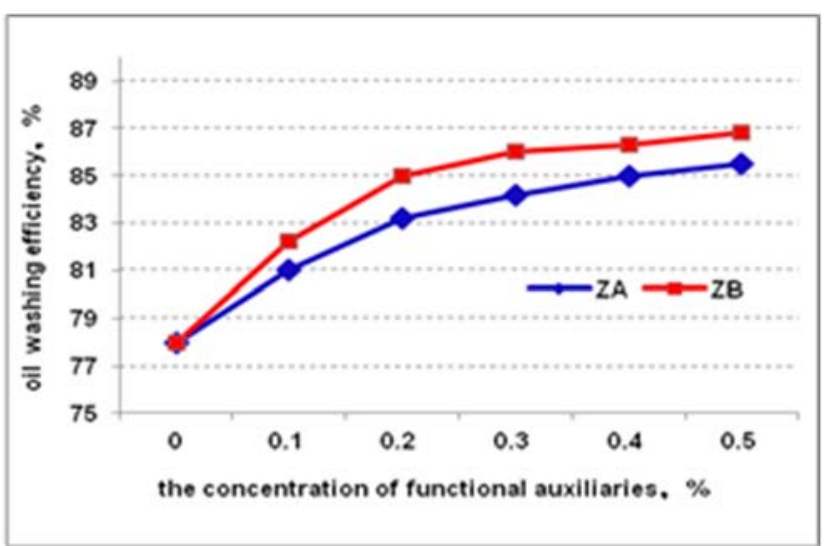

Fig.4 Influence of functional additives on oil washing efficiency

\subsection{Compatibility study of highly effective well flushing fluid with clay stabilizer}

According to the previous research results of composite anti-swelling technology, $\mathrm{KCl}$ and $\mathrm{NH}_{4} \mathrm{Cl}$, two kinds of non-mechanical anti-swelling agents and three kinds of mechanical anti-swelling agents, were added into the high-efficiency well washing fluid according to the 1:1 compound method. Through compatibility investigation, four kinds of multi-functional basic formulations of well washing fluid with good compatibility were obtained, namely XST-1, XST-2, XSK-1 and XSK-2.

Table 1 Experimental results of compatibility between flushing fluid and clay stabilizer

\begin{tabular}{|c|c|c|c|c|c|c|c|}
\hline \multicolumn{2}{|c|}{$\begin{array}{l}\text { Flushing } \\
\text { Fluid system }\end{array}$} & $\begin{array}{c}\text { Experiment } \\
\text { temperature, } \\
25^{\circ} \mathrm{C}\end{array}$ & $\begin{array}{c}\text { The experiment } \\
\text { temperature is } \\
60^{\circ} \mathrm{C}\end{array}$ & $\begin{array}{l}\text { Flushing } \\
\text { Fluid system }\end{array}$ & $\begin{array}{l}\text { Refers to the } \\
\text { standard }\end{array}$ & $\begin{array}{c}\text { Experiment } \\
\text { temperature, } \\
25^{\circ} \mathrm{C}\end{array}$ & $\begin{array}{c}\text { The experiment } \\
\text { temperature is } \\
60^{\circ} \mathrm{C}\end{array}$ \\
\hline \multirow{3}{*}{$\begin{aligned} & \mathrm{XS}-1 \\
&+ 2 \% \mathrm{KCl} \\
&+ 2 \% \mathrm{TDC} \\
&(\mathrm{XST}-1)\end{aligned}$} & Liquid color & $\begin{array}{l}\text { clear and } \\
\text { transparent }\end{array}$ & $\begin{array}{l}\text { clear and } \\
\text { transparent }\end{array}$ & \multirow{3}{*}{$\begin{array}{c}\text { XS- } 1 \\
+2 \% \mathrm{NH}_{4} \mathrm{Cl} \\
+2 \% \mathrm{TDC} \\
(\mathrm{XST}-2)\end{array}$} & Liquid color & $\begin{array}{l}\text { clear and } \\
\text { transparent }\end{array}$ & $\begin{array}{l}\text { clear and } \\
\text { transparent }\end{array}$ \\
\hline & $\begin{array}{l}\text { The } \\
\text { appearance } \\
\text { change }\end{array}$ & nothing & nothing & & $\begin{array}{l}\text { The } \\
\text { appearance } \\
\text { change }\end{array}$ & nothing & nothing \\
\hline & appearance & no precipitation & no precipitation & & appearance & no precipitation & no precipitation \\
\hline
\end{tabular}




\begin{tabular}{|c|c|c|c|c|c|c|c|}
\hline & conclusion & matching & matching & & conclusion & matching & matching \\
\hline \multirow{4}{*}{$\begin{array}{c}\mathrm{XS}-1 \\
+2 \% \mathrm{KCl} \\
+2 \% \mathrm{JK} \\
(\mathrm{XSK}-1)\end{array}$} & Liquid color & $\begin{array}{l}\text { clear and } \\
\text { transparent }\end{array}$ & $\begin{array}{l}\text { clear and } \\
\text { transparent }\end{array}$ & \multirow{4}{*}{$\begin{array}{c}\mathrm{XS}-1 \\
+2 \% \mathrm{NH}_{4} \mathrm{Cl} \\
+2 \% \mathrm{JK} \\
(\mathrm{XSK}-2)\end{array}$} & Liquid color & $\begin{array}{l}\text { clear and } \\
\text { transparent }\end{array}$ & $\begin{array}{l}\text { clear and } \\
\text { transparent }\end{array}$ \\
\hline & $\begin{array}{l}\text { The } \\
\text { appearance } \\
\text { change }\end{array}$ & nothing & nothing & & $\begin{array}{l}\text { The } \\
\text { appearance } \\
\text { change }\end{array}$ & nothing & nothing \\
\hline & appearance & no precipitation & no precipitation & & appearance & no precipitation & no precipitation \\
\hline & conclusion & matching & matching & & conclusion & matching & matching \\
\hline \multirow{4}{*}{$\begin{array}{c}\mathrm{XS}-1 \\
+2 \% \mathrm{KCl} \\
+2 \% \mathrm{JA} \\
(\mathrm{XSA}-1)\end{array}$} & Liquid color & milky white & milky white & \multirow{4}{*}{$\begin{array}{c}\mathrm{XS}-1 \\
+2 \% \mathrm{NH}_{4} \mathrm{Cl} \\
+2 \% \mathrm{JA} \\
(\mathrm{XSA}-2)\end{array}$} & Liquid color & milky white & milky white \\
\hline & $\begin{array}{l}\text { The } \\
\text { appearance } \\
\text { change }\end{array}$ & turbidity & turbidity & & $\begin{array}{l}\text { The } \\
\text { appearance } \\
\text { change }\end{array}$ & turbidity & turbidity \\
\hline & appearance & precipitation & precipitation & & appearance & precipitation & precipitation \\
\hline & conclusion & don't match & don't match & & conclusion & don't match & don't match \\
\hline
\end{tabular}

\subsection{Evaluation of multi-functional and efficient oil pollution cleaning ability of well flushing fluid}

To investigate the affect the oil washing capacity of efficient well flushing fluid under the addition of antiswelling agent, four kinds of multifunctional and efficient well flushing fluids were researched.

The experimental results show that, XST washing fluid has better cleaning effect on crude oil, comparing with the XSK system. Small molecule anti-swelling agent TDC has stronger synergetic effect on well flushing fluid. The temperature is $60^{\circ} \mathrm{C}$, all the four systems have excellent cleaning capability, oil washing efficiency is more than $80 \%$. The performance of oil washing under different temperatures shows that, to achieve a better cleaning effect, the well flushing temperature is recommended to be no lower than $60^{\circ} \mathrm{C}$.

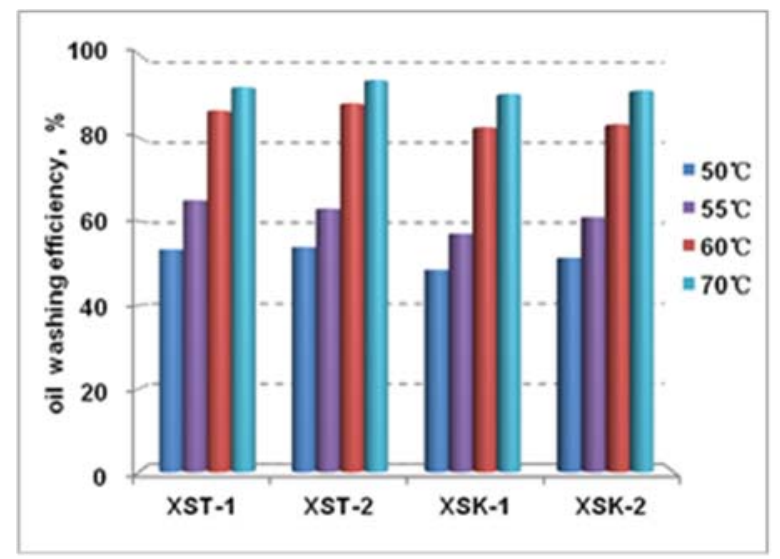

Fig.5 Oil washing efficiency of Different flushing fluid formulations under different temperatures

\subsection{Performance evaluation of multi-functional and efficient cleaning fluid dissolving aged oil}

To investigate the oil washing capacity of efficient well flushing ability under the addition of anti - swelling agent, the multifunctional well flushing fluid was further investigated. Specific test methods are as follows. Take $1 \mathrm{~g}$ aged oil sample (J902 rod and pipe aged oil sample) to the $1.2 \%$ well flushing solution, and then, observed the oil pattern after $0.5 \mathrm{~h}$.

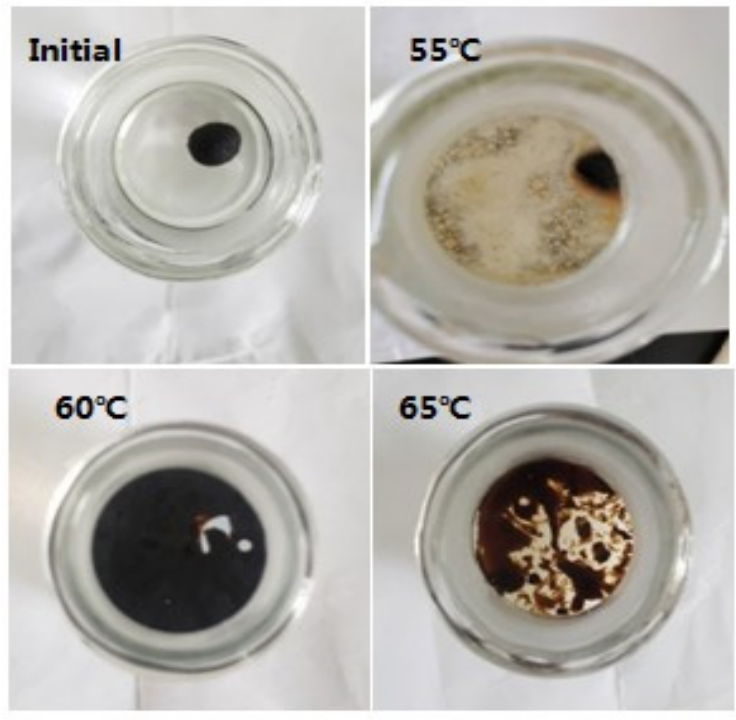

Fig. 6 Evaluation experiment of dissolving Aging oil capacity at different Temperatures (XST-1)

Results of aging oil dissolution test were agreed with oil pollution test results. That was 4 kinds of multifunctional and efficient well flushing fluids. It has excellent ability to dissolve aged oil at $60^{\circ} \mathrm{C}$. 


\subsection{Evaluation of inflation resistance of multi- functional and efficient well flushing fluid}

Centrifugal method was adopted in the expansion prevention experiment (SY/T 5971-2016 Fracturing acidification in oil and gas fields, and the performance evaluation experiment of clay stabilizer for water

Table 2 Experimental results of expansion prevention of different flushing fluid formulations

\begin{tabular}{|c|c|c|c|}
\hline $\begin{array}{c}\text { Flushing fluid } \\
\text { system }\end{array}$ & $\mathrm{V}_{0}(\mathrm{~mL})$ & $\mathrm{V}_{1}(\mathrm{~mL})$ & $\mathrm{B}, \%$ \\
\hline XST-1 & 0.5 & 1.35 & $72 \%$ \\
\hline XST-2 & 0.5 & 1.3 & $74 \%$ \\
\hline XSK-1 & 0.5 & 1.35 & $72 \%$ \\
\hline XSK-2 & 0.5 & 1.3 & $74 \%$ \\
\hline
\end{tabular}

\subsection{Evaluation of inflation resistance of multi- functional and efficient well flushing fluid}

Dynamic core damage evaluation experiments show that,

The damage rate of field water injection to artificial

Table 3 Statistical table of the damage of well flushing fluid and on-site water sample to artificial cemented core

\begin{tabular}{|c|c|c|c|c|c|c|c|c|c|}
\hline $\begin{array}{c}\text { The } \\
\text { serial } \\
\text { number }\end{array}$ & $\begin{array}{c}\text { Core } \\
\text { number }\end{array}$ & $\begin{array}{c}\text { Pore } \\
\text { volume, } \\
\mathrm{mL}\end{array}$ & porosity, o, & $\begin{array}{c}\text { Water } \\
\text { samples }\end{array}$ & $\begin{array}{c}\text { Water phase } \\
\text { permeability, } \\
10^{-3} \mu \mathrm{m}^{2}\end{array}$ & $\begin{array}{c}\text { Displacement } \\
\text { ratio }\end{array}$ & $\begin{array}{l}\text { Water phase } \\
\text { permeability, } \\
10^{-3} \mu \mathrm{m}^{2}\end{array}$ & \begin{tabular}{|c|} 
Core \\
permeability \\
damage \\
value, $\%$ \\
\end{tabular} & $\begin{array}{l}\text { Take the } \\
\text { mean, } \%\end{array}$ \\
\hline 1 & $20 \#$ & 5.2 & 17.37 & sewage & 16.79 & 15 & 7.57 & 54.92 & \multirow{2}{*}{46.63} \\
\hline 2 & $11 \#$ & 6.2 & 18.43 & sewage & 23.4 & 15 & 14.43 & 38.33 & \\
\hline 3 & $21 \#$ & 6.2 & 19.2 & $\begin{array}{c}\text { Flushing } \\
\text { fluid }\end{array}$ & 14.65 & 15 & 12.82 & 12.49 & \multirow{2}{*}{13.97} \\
\hline 4 & $3 \#$ & 6.6 & 19.64 & $\begin{array}{c}\text { Flushing } \\
\text { fluid }\end{array}$ & 15.4 & 15 & 13.02 & 15.45 & \\
\hline
\end{tabular}

Comprehensive evaluation of compatibility, cleaning oil, aging oil solubility, expansion resistance and core damage performance, Developed a highly efficient well flushing liquid formula integrating anti-swelling, cleaning and other functions. This formula has excellent cleaning ability for crude oil with high wax content $(20 \% \sim 35 \%)$ and asphaltene content $(10 \% \sim 40 \%)$. Oil washing

cemented core is up to $46.63 \%$, The degree of damage to core is $33 \%$ higher than that of flushing fluid system; The experimental results show that the multifunctional well flushing fluid has less damage rate to the reservoir than backwater injection. To a certain extent, it can reduce the damage to the formation caused by water used in operation. injection). The anti-swelling rate is evaluated by clay stabilizer solution and water. The experimental well flushing liquid systems is above $70 \%$, Excellent ability to prevent clay swelling. measuring the volume expansion increment of bentonite 


\section{Field application}

Develop efficient well flushing fluid for well J902.The effect is remarkable, the rod and pipe in well $\mathrm{J} 902$ are found as follows: Pull out the sucker rod centralizer connected to the 153 rd sucker rod D19mm lower end in

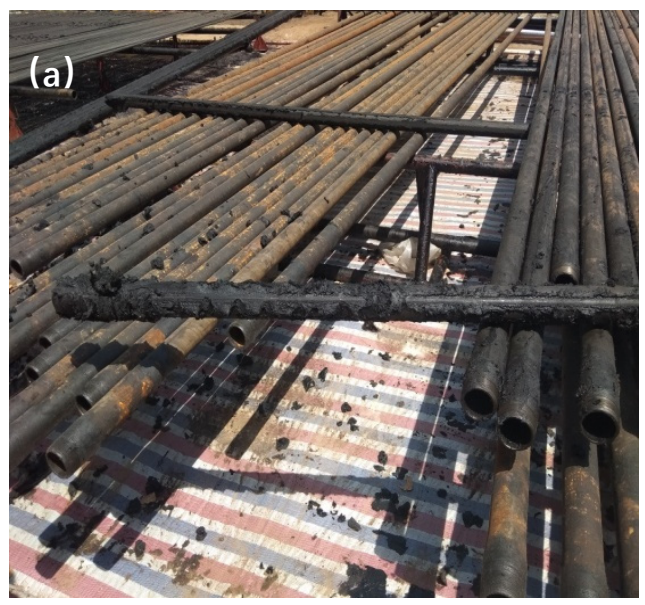

the well, grinding off at the collar of D19mm, and then causing lower pole to fall down. Lift the 133rd thickened tubing D $73 \mathrm{~mm}$. It was found that the end of the root canal was a thickened collar, which had lower string drawdown. The fishing tool suffers from resistance at $670 \mathrm{~m}$ and the hot washing effect is not obvious. After thermal washing with efficient well flushing fluid on site, the fishing tool went in smoothly.

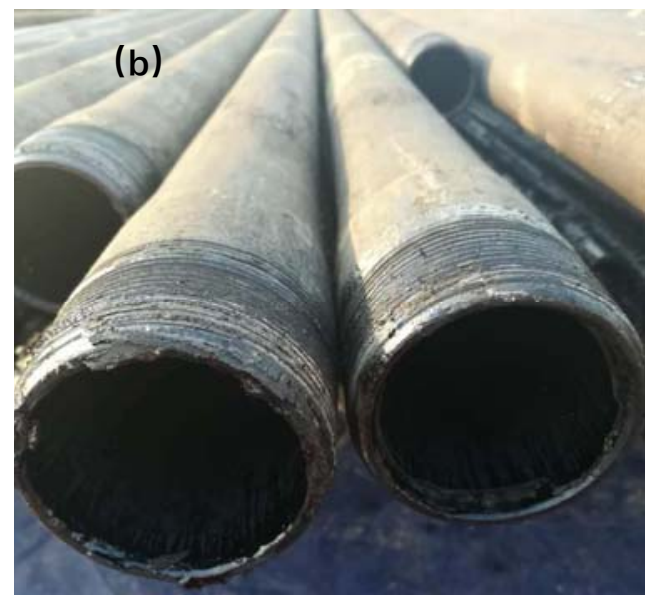

Fig. 7 Effect diagram of J902 tubing and rod before and after cleaning (a) before cleaning (b) after cleaning

\section{Author information}

Miaosen Lu was born in 1991 and is an engineer mainly working on the research of reservoir protection and treatment now. Phone: +86-0317-2782581, E-mail: el_lumiaosen@petrochina.com.cn

\section{Acknowledgements}

This work was financially supported by Science and Technology Project of Huabei Oilfield Company "Research on Reservoir Protection and Treatment Technology in the Process of oilfield development" (2020HB-C12).

\section{References}

1. Du Meimei, Wei Na, Zhao Dongyan, et cl. Study on particle size of polymer microsphere for profile control by using a static laser particle size analyzer. [J]. Oilfield chemistry, 2015, 32 (4): 617-620.

2. Du Rongrong, Liu Xiang. Progress in preparation of acrylamide polymer microsphere by reverse microemulsion polymerization $[\mathrm{J}]$. Progress of chemical engineering, 2015, 34 (8): 3065-3074.

3. Lin Weimin, Chen Yonghao, Cao Min, et cl. Performance evaluation and application of $\mathrm{YG}$ polymer microsphere for deep profile control agent [J]. Oil and gas field development and mining, 2011, 28 (3): 327-330.

4. Lou Zhaobin, Li Dishu, Fan Aixia, et cl. Study and application of polymer microsphere flooding control in Wen 25 east block of Zhongyuan Oilfield [J].
Journal of Southwest Petroleum University, 2012, 34 (5): 125-132.

5. Zhu Yanjie. Research and application of polymer microsphere profile control technique in three north field oil field [D]. Beijing, China University of Petroleum (Beijing), 2010.

6. Eric D, Brigitte B, David R. Chemical EOR for Heavy Oil: the Canadian Experience[R], SPE 169715MS,2014.

7. Xue Wei. Improve the oil displacement agents of flexible micro gel [Q], the recovery rate of Beijing, according to the Beijing Kerui Energy Technology Development Co. Ltd, 2016.

8. Cui Guoyou. To improve the oil displacement agent flexible gel /SMG series [Q], the recovery rate of Beijing, Beijing startwell new Mstar Technology Ltd, 2015.

9. Song Hongtao, Chen Liang. Oil with deep profilecontrol agent JBT-WQ [Q] elastic polymer ball, Beijing, Beijing, Czech Bote Energy Technology Co. Ltd, 2016.

10. Wei Na, Yu Jing, Ma Wenheng, et cl. With flexible micro gel technology specification [Q], flooding, Renqiu, Huabei Oilfield Company of PetroChina Co Ltd, 2015. 